\title{
Efeito de um composto de leveduras na incidência de diarreia em bezerras criadas em diferentes sistemas de alojamento
}

\author{
Scherer, B. ${ }^{\text {; }}$ Pizoni, C. '; Cardoso, K.B. '; Barbosa, A.A. ${ }^{@}$; Raimondo, R.F. e S. ${ }^{2}$; Ladeira, S.R.L. ${ }^{3}$; Brauner, C.C. ' ; Del Pino, \\ F.A.B. ${ }^{\text {; }}$ Corrêa, M.N. ${ }^{1}$ e Rabassa, V.R. ${ }^{1}$
}

'Nupeec-Núcleo de Pesquisa, Ensino e Extensão em Pecuária. Universidade Federal de Pelotas. Pelotas. Brasil. ${ }^{2}$ Núcleo Ruminação - Ensino, Pesquisa e Extensão em Ruminantes. Universidade Federal do Rio Grande do Sul. Porto Alegre. Brasil. ${ }^{3}$ LRD - Laboratório Regional de Diagnóstico, Universidade Federal de Pelotas. Pelotas. Brasil.

\section{PalaVRas chaVe adicionais}

Agentes.

Criação ao ar livre.

Desempenho.

Enfermidades.

Saccharomyces.

\section{RESUMO}

O objetivo do presente estudo foi avaliar o efeito da suplementação de um produto composto de cultura de levedura e levedura enzimaticamente hidrolisada na incidência de diarreia e no desenvolvimento corporal de bezerras leiteiras submetidas à diferentes sistemas de alojamento. Foram usadas cento e dezenove bezerras mantidas em dois sistemas de alojamento e divididas aleatoriamente em dois grupos: grupo levedura $(n=62,36$ ao ar livre e 26 no curral) e grupo controle $(n=57,30$ ao ar livre e 27 no curral). O grupo levedura foi tratado com $8 \mathrm{ml}$ de cultura de levedura / animal, que foi administrada oralmente uma vez por dia durante 42 dias. As medidas zootécnicas foram analisadas e a incidência de diarreia infecciosa foi monitorada, também foram realizadas coletas de sangue e fezes. Os dados foram submetidos à análise de variância por medidas repetidas do Software SAS, Tukey's HSD e Teste Qui quadrado, sendo considerado diferença estatística $(p \leq 0,05)$. Os animais do grupo controle criados ao ar livre apresentaram maior incidência de diarreia $(80,00 \%)$ quando comparado aos animais do grupo tratamento $(55,55 \%)(p=0,03)$. O período de maior incidência de diarreia $(96,92 \%)$ foi nos primeiros 15 dias de vida $(p<0,001)$. As análises bacteriológicas de fezes mostraram que 53,38\% apresentaram Enterococcus sp. e 46,61\% Eschechiria coli. Após o diagnóstico de diarreia, ambos os grupos (controle e levedura) apresentaram leucocitose. Conclui-se que a suplementação oral de levedura para animais criados ao ar livre foi capaz de reduzir os efeitos dos desafios causados por esse sistema, diminuindo a incidência de diarreia.

\section{Effect of a yeast compound on the incidence of diarrhea in calves raised in different housing systems}

\section{SUMMARY}

\section{ADDITIONAL KEYWORDS \\ Agents. \\ Diseases.}

Performace.

Saccharomyces.

Outdoor creation.

\section{INFORMATION}

Cronología del artículo.

Recibido/Received: 15.04.2020

Aceptado/Accepted: 27.08.2020

On-line: 15.10 .2020

Correspondencia a los autores/Contact e-mail:

antoniobarbosa.vet@hotmail.com.
The aim of the present study was to evaluate the effect of supplementation of a product composed of yeast culture and enzymatically hydrolyzed yeast on the incidence of diarrhea and on the body development of dairy calves submitted to different housing systems. One hundred and nineteen calves were used in two housing systems and randomly divided into two groups: yeast group $(n=62,36$ outdoors and 26 in the corral) and control group ( $n=57,30$ outdoors and 27 in the corral). The yeast group was treated with $8 \mathrm{ml}$ of yeast / animal culture, which was administered orally once daily for 42 days. The zootechnical measures were analyzed and the incidence of infectious diarrhea was monitored, blood and feces were also collected. The data were submitted to analysis of variance by repeated measures of the SAS Software, Tukey's HSD and Chi-square test, being considered a statistical difference ( $p \leq 0.05)$. The animals in the control group raised outdoors had a higher incidence of diarrhea $(80.00 \%)$ when compared to animals in the treatment group (55.55\%) ( $p=0.03$ ). The period with the highest incidence of diarrhea (96.92\%) was in the first 15 days of life $(p<0.001)$. The bacteriological analysis of feces showed that $53.38 \%$ had Enterococcus sp. and $46.61 \%$ Eschechiria coli. after the diagnosis of diarrhea, both groups (control and yeast) presented leukocytosis. It is concluded that oral yeast supplementation for animals raised in the open was able to reduce the effects of the challenges caused by this system, decreasing the incidence of diarrhea.

\section{INTRODUÇÃO}

O ciclo de produção da cadeia leiteira é constituído de diferentes fases que se apresentam interligadas, sendo assim qualquer erro em uma dessas etapas culminará com reflexos negativos no decorrer da cadeia e, consecutivamente, prejuízos econômicos. Neste contexto, a criação de bezerras com baixos índices de enfermidades assume um papel fundamental no que tange a excelência da expressão da real capacidade produtiva dessa futura vaca leiteira (Kuczaj et al. 2019, p. 955).

Contudo, normalmente, a fase de criação das bezerras é a que recebe menor atenção por parte do produtor justamente por não proporcionar retorno econômi- 
co direto, ficando por muitas vezes em segundo plano, gerando, como consequência, altas taxas de morbidade e de mortalidade. No Brasil, estima-se que o número de óbitos nesta fase inicial de vida fique em torno de $15 \%$ (Machado Neto et al. 2004, p. 2323) oriundos de distúrbios entéricos e respiratórios, como a diarreia e broncopneumonia, configurando essas doenças como as principais causas de óbito nesse momento (Maunsell \& Donovan 2008, p. 155; Lora et al. 2018, p. 12).

A diarreia caracteriza-se por ser uma enfermidade de causas multifatoriais, resultante da interação entre agentes infecciosos e fatores não infecciosos, relacionados ao manejo. As perdas econômicas relacionadas a esta doença são principalmente ligadas ao retardo no crescimento e mortalidade dos animais leiteiros (Patês et al. 2012, p. 825) com um custo global equivalente a US\$ 33,46 bezerro/ano (Silva et al. 2019, p. 1).

Grande parte das estratégias profiláticas preconiza somente a adequada ingestão de colostro rico em globulinas nas primeiras 24 horas de vida, no entanto outras alternativas também são mencionadas na literatura como, a utilização de produtos homeopáticos, lactoferrina, extrato de alho, óleos essenciais isoladamente ou em combinação com antimicrobianos comuns e probióticos (Torrezan et al. 2016, p. 508; Fortuoso et al. 2017, p. 95; Habing et al. 2017, p. 3940; Solarte et al. 2017, p. 1). Aliado a isso, alternativas com apelo sustentável, vem ganhando força dentro dos sistemas de produção, uma vez que visam diminuir a utilização indiscriminada de antibióticos. Neste contexto a utilização de leveduras para episódios de diarreia vem se tornando uma boa opção.

Culturas de leveduras são consideradas como aditivos para utilização na produção animal, de acordo com Food and Drug Administration (FDA; 2014) e são amplamente disseminadas uma vez que o mercado internacional busca por alternativas que visam diminuir o uso indiscriminado de antibióticos em animais de produção, pois essa pratica é fator importante para a disseminação de cepas resistentes a medicamentos resultado em sérias consequências para a saúde pública, indústria de alimentos e animais (EFSA, 2015; ECDC, 2014). As leveduras Saccharonyces cerevisiae, são divididas em: leveduras vivas na qual desempenham a sua função no organismo quando estiverem na forma ativa; e as leveduras hidrolisadas (Nocek et al. 2011, p. 4046). Os produtos comerciais podem ser compostos por apenas uma classe de levedura ou pelo composto, levedura viva e hidrolisada. Os efeitos dessa suplementação variam desde a manutenção da saúde da microflora intestinal até a modulação da resposta imune (Coppola et al. 2005, p. 213; Kim et al. 2011, p. 953). Além disso parecem ter influência na fermentação atuando principalmente na população dos microrganismos do rúmen (Robinson \& Erasmus 2009, p. 185).

Tais efeitos ocorrem pelo fato desses compostos possuírem mananoligossacarídeos (MOS), substâncias que auxiliam no correto funcionamento do trato gastrointestinal (Nocek et al. 2011, p. 4046) estimulando de maneira seletiva o crescimento e a atividade de bactérias não-patogênicas no cólon (Spring et al. 2000, p. 205; Fairchild et al. 2001, p. 562; Parks et al. 2001, p. 718; Gosh et al. 2011, p. 449). Além dos MOS, as leveduras também possuem em sua parede celular os glucanos, que caracterizam-se por ter propriedades imunomodulatorias de polissacarídeos as quais são capazes de estimular macrófagos através da ativação do sistema complemento (Vetvicka \& Vevichova 2007, p. 225; Czech et al. 2018, p. 221; Boudergue et al. 2009, p. 1). Entretanto, a resposta de neonatos à suplementação da levedura Saccharomices cereviseae depende dos fatores de risco a que estão expostos como, tipo de alojamento, lotação, exposição à estresse ambiental e higienização do ambiente entre outros (Silva Junior et al. 2011, p. 690; Cole et al. 1992, p. 1682), os quais podem ser afetados pelo manejo e sistema de alojamento (Wójcik et al. 2013, p. 628).

Sendo assim o objetivo do presente estudo foi avaliar o efeito da suplementação de um produto composto de cultura de levedura e levedura enzimaticamente hidrolisada na incidência de diarreia e no desenvolvimento corporal de bezerras leiteiras submetidas à diferentes sistemas de alojamento.

\section{MATERIAIS E METODOS}

A utilização dos animais no experimento foi realizada de acordo com as normas do Comitê de Ética em Experimentação Animal da Universidade Federal de Pelotas - código 436.

O experimento foi conduzido em uma fazenda de produção leiteira localizada em Rio Grande, Rio Grande do Sul, Brasil; durante aproximadamente 150 dias no período de outono/inverno. A temperatura ambiente foi monitorada diariamente por uma estação meteorológica em Rio Grande (coordenadas 32,07 $\mathrm{S}$; $\left.52,16^{\circ} \mathrm{O}\right)$.

\section{Seleção dos Animals e Grupos Experimentals}

Cento e dezenove bezerras foram avaliadas durante seis semanas após 24 horas do nascimento. Os animais foram separados das vacas 24 horas após o parto e, neste período, foi permitida a amamentação espontânea do colostro. Para a seleção dos animais, assim que as bezerras eram separadas das mães, coletava-se uma amostra de sangue da veia jugular, armazenando-a em tubo contendo o anticoagulante ácido etilenodiamino tetra acético (EDTA). A amostra era centrifugada e o plasma resultante era avaliado através de um refratômetro portátil para medir os níveis de proteína plasmática total (PPT). Bezerras que apresentassem níveis de PPT menores que $0,5 \mathrm{~g} / \mathrm{dL}$ eram excluídas do experimento, devido à baixa concentração de imunoglobulinas no sangue (Borges et al. 2001, p. 629).

As bezerras selecionadas para o estudo foram alojadas aleatoriamente em dois sistemas, confinadas em baias individuais ou acondicionadas ao ar livre e mantidas em estacas de contenção fixadas a um ponto central. Os animais recebiam quatro litros de leite por dia, além de concentrado peletizado composto por $18 \%$ de proteína e $8 \%$ de fibra. O concentrado foi fornecido gradualmente e os animais tiveram acesso à água ad libitum de acordo com o manejo da propriedade seguindo os Requerimentos Nutricionais de Bovinos Leiteiros (NRC 2001). 
Os animais estudados foram divididos aleatoriamente em dois grupos. Grupo Levedura $(n=62$, sendo um $n=36$ ao ar livre e $n=26$ em baias) e Grupo Controle ( $n=57$, sendo um $n=30$ ao ar livre e $n=27$ em baias). A cultura de levedura e a levedura enzimaticamete hidrolisada (Celmanax, Arm \& Hammer Animal Nutrition, Princiton, NJ) foram administrados por via oral a uma dose de $8 \mathrm{~mL}$ por animal, uma vez ao dia, por seis semanas a partir de 24 horas após o nascimento.

\section{Desempenho do CRESCIMENTO}

Para avaliação do desenvolvimento dos animais as medidas de Peso corporal $(\mathrm{Kg})$ - PC, perímetro torácico $(\mathrm{cm})$ - PT, altura da cernelha $(\mathrm{cm})$ - AC e largura da garupa $(\mathrm{cm})$ - LG, foram avaliados a cada sete dias com fitas de medição específicas, durante seis semanas conforme metodologia de Sampaio (1990, p. 27).

\section{Diagnóstico, Tratamento e Coleta de Fezes}

Os animais eram monitorados diariamente e tinham seu comportamento e escore de fezes observados. O escore de fezes variava entre 1 e 4 (Magalhães et al. 2008 , p. 1497). Escores 3 e 4 eram caracterizados com diarreia e amostras eram coletadas para análise bacteriológica. A condição clínica dos animais era avaliada através de exame clínico geral sempre que houvesse casos de diarreia. Os parâmetros avaliados eram a frequência cardíaca, frequência respiratória, temperatura retal e tempo de preenchimento capilar (TPC).

Animais com sinais de diarreia eram submetidos à antibioticoterapia com combinações de trimetoprim e sulfadiazina (Tribisem, InverSchering - Plough, Brasil); a administração era via intramuscular a uma dose de 15 mg Kg -1 de peso corporal. Bezerros mostrando sinais de desidratação eram submetidos a fluidoterapia através de solução de ringer e sódio lactato (Basa ${ }^{\circledR}$, Brasil); o volume variava com o grau de desidratação do animal.

As amostras de fezes eram coletadas para análise bacteriológica segundo metodologia apresentada em Brandi et al. (2016, p. 527) sempre que os animais avaliados apresentassem sinais de diarreia. As amostras eram coletadas e enviadas para a seção de bacteriologia do Laboratório Regional de Diagnóstico (LRD) da Universidade Federal de Pelotas- UFPel.

As colônias eram caracterizadas quimicamente. Ademais, as amostras fecais da população investigada eram coletadas mensalmente, durante todo o período de experimento, para monitorar os níveis de infestação de parasitas, com base na técnica de Gordon e Whitlock (1939, p. 50).

\section{Amostras de SANGUe}

As amostras de sangue eram coletadas para análise de leucócitos totais no dia em que a diarreia. começava para determinar a possível origem da diarreia. A coleta de sangue era realizada com tubos com vácuo contendo anticoagulante EDTA. A contagem do número total de leucócitos era realizada através do contador automático DC-359 (CELM, São Paulo, Brasil).
Os resultados do presente estudo foram submetidos a análise de variância por medidas repetidas no software SAS (1986); médias (grupos, coletas, grupos $x$ coletas e grupo $x$ sistema de criação) foram comparadas através do teste Tukey's HSD ( $\mathrm{p} \leq 0,05)$. Finalmente, os animais foram separados em dois grupos com base na ocorrência ou não de diarreia (saudável ou doente) para evitar resultados possivelmente mascarados pela incidência da doença e para permitir a análise dos parâmetros de crescimento (peso corporal, ganho médio diário, perímetro torácico, largura de garupa e altura de cernelha). O teste Qui quadrado foi utilizado para avaliar a incidência de diarreia (grupo e grupo $\mathrm{x}$ sistema de criação).

\section{RESULTADOS}

Nos animais criados ao ar livre o Grupo Controle apresentou maior incidência de diarreia $(80,00 \%$ 24/30) comparado ao Grupo Levedura (55,55\% 20/36, $\mathrm{p}=0,03)$; entretanto, não houve diferença entre o Grupo Controle $(66,67 \%$ 18/27) e o Grupo Levedura (84,61\% $22 / 26, p=0,13)$ para os animais criados em baias. Para avaliar o efeito do tratamento aplicado foi realizado a comparação entre os grupos Controle e Levedura sem levar em consideração os sistemas de alojamento, foi observado que os grupos Controle e Levedura não diferiram para a incidência de diarreia $(p=0,48)$; $E m$ relação ao período de maior incidência de diarreia, $96,92 \%(63 / 65, p<0,001)$ dos casos ocorreram nas duas primeiras semanas de vida dos animais, independente do sistema de alojamento.

As análises bacteriológicas mostraram que 53,38\% da amostra fecal apresentaram Enterococcus sp., 47,61\%, Eschechiria coli, 33,33\%, poliflora bacteriana e 4,76\% não apresentaram crescimento bacteriano. Infestações de parasitas não foram identificadas nos animais estudados.

Na avaliação zootécnica não houve diferença entre os animais que não apresentaram diarreia (saudáveis) nos diferentes tratamentos e sistemas $(p>0,05)$. No entanto na mesma comparação com os animais que apresentaram diarreia (doentes) (Tabela I), observou-se diferença entre sistemas, no crescimento da largura de garupa (LG) onde os animais mantidos em baias individuais apresentaram maiores valores médios de LG quando comparados aos animais mantidos ao ar livre ( $p=0,01$ e não houve diferença nos parâmetros de crescimento em animais com diarreia que receberam a levedura em comparação ao grupo controle ( $p>0,05)$.

Os grupos Controle e Levedura não diferiram entre si para os parâmetros clínicos (Tabela 2). Após o diagnóstico da diarreia, os dois grupos apresentaram leucocitose nos dois sistemas (Grupo Levedura = 18,507/ $\mu \mathrm{L}$; Grupo Controle $=19,066 / \mu \mathrm{L}, \mathrm{p}=0,8944$ (Tabela 2); baias individuais $=17,112 / \mu \mathrm{L}$; ao ar livre $=20,461 / \mu \mathrm{L}$, $p=0,4303)$. No entanto houve diferença estatística para o número de eosinófilos, sendo o grupo Controle o que apresentou maior contagem quando comparado ao grupo Levedura (Tabela II). 


\begin{tabular}{|c|c|c|c|c|c|}
\hline \multirow[b]{2}{*}{ Parâmetros } & \multicolumn{2}{|c|}{ Grupos } & \multicolumn{3}{|c|}{ Valor de $\mathrm{P}$} \\
\hline & Levedura & Controle & Grupo & Coleta & Grupo x Coleta \\
\hline Peso corporal (kg) & $47,9(0.5)$ & $48,3(0.5)$ & 0,59 & 0,0001 & 0,29 \\
\hline Altura de cernelha $(\mathrm{cm})$ & $81,3(0,4)$ & $81,5(0,4)$ & 0,80 & 0,0001 & 0,24 \\
\hline Circunferência de tórax (cm) & $81.2(0.3)$ & $81.3(0.3)$ & 0,91 & 0,0001 & 0,91 \\
\hline Largura de Garupa (cm) & $29.3(0.2)$ & $29.1(0.2)$ & 0,26 & 0,0001 & 0,95 \\
\hline
\end{tabular}

Tabela II. Parâmetros clínicos e hematológicos sobre a ocorrência de sinais clínicos de diarreia em bezerros suplementados com levedura e levedura hidrolisada enzimaticamente (Clinical and hematological parameters on the occurrence of clinical signs of diarrhea in calves supplemented with yeast and enrhesilyded hydrolyzed yeast).

\begin{tabular}{|c|c|c|c|}
\hline \multirow{2}{*}{ Parâmetros } & \multicolumn{2}{|c|}{ Grupos } & \multirow{2}{*}{ Valor de $\mathrm{P}$} \\
\hline & Levedura & Controle & \\
\hline Frequência cardíaca (batimentos / min) & $112,5 \pm 4,4$ & $112,0 \pm 9,2$ & 0,93 \\
\hline Frequência respiratória (movimentos / min) & $30,6 \pm 2,1$ & $30,8 \pm 4,0$ & 0,93 \\
\hline Tempo de preenchimento capilar (segundos) & $2,4 \pm 0,1$ & $2,6 \pm 0,2$ & 0,48 \\
\hline Temperatura retal $\left({ }^{\circ} \mathrm{C}\right)$ & $38,8 \pm 0,1$ & $39,1 \pm 0,2$ & 0,63 \\
\hline Eritrócitos $\left(\times 10^{6} / \mu \mathrm{L}\right)$ & $8,3 \pm 0,4$ & $9,1 \pm 1,2$ & 0,50 \\
\hline Hematocrito (\%) & $30,5 \pm 1,7$ & $28,4 \pm 1,7$ & 0,36 \\
\hline Hemoglobina (g/dL) & $9,5 \pm 0,5$ & $9,3 \pm 0,7$ & 0,65 \\
\hline Total de leucocitos $(/ \mu \mathrm{L})$ & $18.700 \pm 2,100$ & $19.000 \pm 3,100$ & 0,89 \\
\hline Neutrófilos segmentados $(/ \mu \mathrm{L})$ & $8.283,5 \pm 1.264,1$ & $14.162,2 \pm 7.054,2$ & 0,19 \\
\hline Neutrófilos bastonetes $(/ \mu \mathrm{L})$ & $635,9 \pm 162,5$ & $2.205,3 \pm 1.696,4$ & 0,09 \\
\hline Linfócitos $(/ \mu \mathrm{L})$ & $7.456,9 \pm 1.262,5$ & $8.160,5 \pm 1.891,3$ & 0,77 \\
\hline Eosinófilos $(/ \mu \mathrm{L})$ & $139,9 \pm 41,3$ & $431,5 \pm 229,2$ & 0,05 \\
\hline Monocitos $(/ \mu \mathrm{L})$ & $1.744,3 \pm 508,5$ & $1.604,4 \pm 1,474,9$ & 0,08 \\
\hline Proteína plasmática total (g/dL) & $6,8 \pm 0,3$ & $7,6 \pm 0,9$ & 0,11 \\
\hline Fibrinogenio (mg/dL) & $475,0 \pm 149,3$ & $266,6 \pm 66,6$ & 0,37 \\
\hline
\end{tabular}

A suplementação com levedura diminuiu a incidência de diarreia em animais criados ao ar livre uma vez que esse modelo de sistema de criação resulta em maior desafio imunológico aos recém-nascidos. Esse resultado corrobora com o estudo de Klein-Jöbstl et al (2014, p. 5110), onde foi observado maior incidência de diarreia em bezerros alojados em baias ao ar livre quando comparado com animais alojados em baias dentro de um celeiro, sendo esse resultado justificado pelas oscilações da temperatura que os animais ao ar livre estavam expostos, supondo que os neonatos são vulneráveis a variação de temperatura tornando-os mais propensos a determinadas doenças.

Bezerros neonatos podem tolerar temperaturas baixas, por serem capazes de acelerar o metabolismo, aumentando a produção de calor através da utilização do tecido adiposo marrom (TAM) (Hänninen et al. 2003 p.21). A principal atividade do TAM é a utilização de energia proveniente da lipólise para a geração de calor em recém-nascidos. Para isso, os trigliceridios são quebrados liberando ácidos graxos, que entram na mitocôndria do adipócito marrom para sofrerem oxidação sendo estimuladas pela proteína desacopla- dora-1 (UCP-1) gerando energia, que é desviada para a síntese de calor (Fonseca-Alaniz et al. 2006, p.216). Com isso acreditasse que apesar de bezerros recém-nascidos serem resistentes a temperaturas baixas, são vulneráveis a variação de temperatura, o que resulta em maior incidência de diarreia em bezerros criados ao ar livre, quando comparados aos bezerros criados em celeiros. Apesar dos ambientes fechados também estarem expostos a temperaturas críticas, são menos propensos a amplitude térmica, o que é benéfico, levando os bezerros a um maior conforto térmico e menor incidência de doenças (Hänninen et al. 2003, p. 21; Campos et al. 2005, p. 153). Esse resultado está de acordo com outros autores que relatam que bezerras criados em bezerreiros sem boa ventilação ou submetidos a estresse por frio ou calor tem grande risco de desenvolver doenças, pois nestas situações o desafio ambiental sobrepõe à capacidade do sistema imune do animal, então é necessário que eles estejam em um ambiente o mais apropriado e confortável possível, para manter a homeostase do organismo, e então dar continuidade ao seu desenvolvimento (Coelho 2009, p.1). 
Sabe-se que além do ambiente influenciar na ocorrência de diarreia, os agentes infecciosos também estão entre os principais responsáveis pela ocorrência dessa doença em sistemas leiteiros (Lora et al. 2018, p. 12). Os principais agentes causadores da diarreia neonatal bovina são as bactérias Escherichia coli. e Salmonella spp., ambas caracterizadas como bactérias gram-negativas (Silva et al. 2019, p. 1; Narimatsu et al. 2019, p. 179). No presente estudo os agentes mais diagnosticados foram Enterococcus sp. e Eschechiria coli. resultado semelhante ao da pesquisa conduzida por Pianta (1993, p. 107) que realizou isolamento bacteriano em 1720 amostras de fezes de bezerros e encontrou que em 72,3\% das amostras tinham a presença de E. Coli e 10,6\% apresentaram Salmonella Dublin, todavia corroborando com o encontrado por Cho et al. (2013, p. 375) onde demonstraram que existem diferentes agentes causadores de diarreia de acordo com o ambiente e sistema de manejo. Contudo, independente do agente causador, encontrar alternativas que minimizem o efeito negativo destes patógenos é de vital importância para prevenção e tratamento desta enfermidade.

Com isso as leveduras tem um papel importante nessa prevenção, pois apresentam MOS que agem como ligantes de alta afinidade, sendo responsáveis por competir pelos sítios de ligação com as bactérias gram negativas, resultando na diminuição da colonização do trato gastrointestinal (Nocek et al. 2011, p. 4046).

Os $\beta$-glucanos, como já mensionados, são responsáveis por desencadear respostas antigênicas melhorando a imunidade humoral de animais suplementados com leveduras (Ferket 2003, p. 57). Essas substâncias também estão relacionadas com a ativação das células do sistema imune aumentando a taxa de fagocitose e a resposta a patógenos (Boudergue et al. 2009, p. 1). Isso nos leva a acreditar que o efeito benéfico encontrado nos animais suplementados com levedura está associado a competitividade pelos sítios de ligação que ocorre entre a levedura hidrolisada enzimaticamente e os patógenos e, associada a melhora do sistema imune, resultou na diminuição da incidência de diarreia no grupo mais desafiado a intempéries ambientais. Fato esse que talvez explique o porquê que animais suplementados mesmo com número semelhante no leucograma tenham menores índices de incidência de diarreia.

Os parâmetros zootécnicos avaliados no presente estudo não apresentaram diferença entre os grupos. Resultados semelhantes foram citados na literatura, uma vez que, bezerras da raça holandesa quando foram suplementadas durante a fase de aleitamento com leveduras não apresentaram efeitos significativos para desempenho (peso corporal, ganho médio diário, eficiência alimentar e parâmetros zootécnicos) (Pinos-Rodriguez et al. 2008, p. 223; Fokkink et al. 2009, p. 794; Huuskonen \& Pesonen 2015, p. 295). No entanto esperava-se que os animais suplementados com levedura e que tiveram diarreia apresentassem resultados melhores do que os animais do Grupo Controle que tiveram diarreia. Dado que a suplementação de levedura está associada a maiores taxas de ingestão de matéria seca (IMS) e aumento no ganho de peso em ruminantes e não-ruminantes (Gao et al. 2008, p. 1377; Haddad \&
Goussous 2005, p. 343). Fato esse corroborado por Ding et al (2008, p. 547), no qual ovinos suplementados com levedura viva apresentaram 7,3\% de melhora na conversão alimentar (CA) em relação ao grupo controle.

A adição de levedura na dieta de ruminantes traz benefícios para o ambiente ruminal, uma vez que aumenta a população de bactérias fermentadoras de celulose, amido e açucares (Jiang et al. 2017, p. 8102). Fazendo com que aumente a concentração de ácidos graxos voláteis totais no rúmen, devido a melhora na digestibilidade dos nutrientes, além de aumentar a excreção de derivados de purina, indicando que a suplementação beneficia a síntese de proteína microbiana ruminal, através do aporte energético (Zhu et al. 2017, p. 36). No entanto acreditamos que resultados semelhantes não foram demostrados em nosso estudo uma vez que, o rúmen do neonato só estará totalmente desenvolvido entre 14 e 16 semanas de idade (Sato et al. 2010, p. 1471), e a maior ocorrência de doenças infectocontagiosas e parasitárias se dá nas primeiras 4 semanas de vida (Silva et al. 2019, p. 1) , momento em que o rúmen ocupa somente $20 \%$ do volume total de todo o sistema digestório dos ruminantes (Sato et al. 2010, p. 1471).

O tratamento dos animais logo após o diagnóstico pode também ter influenciado neste resultado, uma vez que permitiu que os animais do Grupo Controle tivessem perdas menores. Por outro lado, animais com diarreia e criados em ambiente fechado apresentaram aumento na largura de garupa em comparação aos mantido ao ar livre. Esse resultado pode estar atrelado ao fato de os animais criados em ambientes fechados apresentarem menos desafiados que os criados ao ar livre. A exposição ao frio, característico de sistemas de alojamento ao ar livre, resultam em mudanças adaptativas, sendo uma delas o aumento do consumo, dado que o estresse ao frio a longo prazo pode aumentar a exigência nutricional dos bezerros para suprir o gasto de energia destinado para a manutenção da temperatura corporal, a literatura mostrou resultados que comprovam essa especulação, onde mostra que bezerros alojados a $-4^{\circ} \mathrm{C}$ requeriam $32 \%$ mais energia para manutenção do que bezerros alojados a $+10^{\circ} \mathrm{C}$. (Hepola et al. 2006, p. 94; Hanninen et al. 2003, p. 21; Scibilia et al. 1987 , p. 1426

Os leucócitos desempenham um papel essencial na defesa imunológica dos neonatos durante o primeiro mês de vida, sendo essencial nos primeiros 15 dias, dado que é a fase mais crítica para a ocorrência de casos de diarreia (Roland et al., 2014, p. 1). Após o diagnóstico da diarreia, os dois grupos apresentaram leucocitose, o que induz a acreditar que nesse período os animais estavam mais desafiados, sendo numericamente o grupo levedura o que apresentou menos leucócitos e menor incidência de enfermidades, a partir disso é possível especular que provavelmente a qualidade da resposta imune seja um fator chave nesse processo, essa afirmação é sustentada por resultados encontrados na literatura, de acordo com Lin et al. (2019, p. 1586) cães suplementados com $250 \mathrm{mg}$ de levedura Saccharomices Cerevisiae apresentaram menor $(\mathrm{p}<0,05)$ contagem total de leucócitos do que os animais do grupo controle. Outro estudo conduzido por Shen et 
al (2011, p. 2462) encontraram resultados semelhantes, onde foi demostrado aumento nos níveis de T helper- 1 (Th1), células responsáveis por maximizar a atividade fagocítica dos macrófagos, no intestino de suínos que foram alimentados com levedura, esse resultado foi associado a capacidade dos ß-glucanos da parede celular das leveduras em desencadear respostas Th1.

As leveduras trazem benefícios para o organismo animal, no entanto segundo a Comissão Europeia -EFSA a levedura Saccharomyces cereviviae é considerado um potencial irritante para a pele e os olhos, também é mencionado o seu efeito sensibilizador da pele e do sistema respiratório, sendo perigoso quando inalado pelos animais (EFSA 2019, p. 5915; EFSA 2020, p. 6144). Quando as leveduras foram empregadas na alimentação de humanos apresentaram em alguns trabalhos efeitos adversos como a ocorrência de Fungemia, doença que consiste na presença de fungos no sangue, ocasionada em pacientes imunocomprometidos (Herbrecht \& Nivoix 2005, p.1635; Roy et al. 2017, p.1).

As leveduras são amplamente utilizadas nos sistemas de produção, podendo ser adicionadas na dieta na forma de levedura viva, na qual vão desempenhar o seu papel quando viáveis no ambiente ruminal, atuando na captação do oxigênio (Marden et al. 2008, p. 3528) e na forma hidrolisada que são aquelas que utilizam a parede celular de leveduras mortas e, dependendo do processo de hidrolise, fará com que ocorra a exposição dos componentes celulares (MOS, ß-glucanos) (Nocek et al. 2011, p. 4046) ou aqueles produtos compostos, no qual utilizam ambos os tipos de levedura. O presente estudo utilizou um produto composto para prevenir a incidência de diarreia, devido a isso não é possível elucidar de forma clara e objetiva qual o tipo de levedura que melhor atuou nessa enfermidade. No entanto acredita-se que a levedura hidrolisada tem melhor efeito no sistema imunológico por apresentar os componentes da parede celular mais expostos (Pitarch et al. 2008, p. 217), sendo então, capazes de interferir na resposta imune dos bezerros.

Além disso a colostragem com colostro de baixa qualidade, fato esse que não ocorreu no presente estudo, é um fator de risco para a presença de diarreia (Al-Alo et al. 2018, p. 3; Lora et al. 2018, p. 12) e a altas taxa de mortalidade nas primeiras semanas de vida, exatamente o período onde ocorreu maior incidências dessa enfermidade. Esse resultado demonstra como os bezerros são sensíveis a este período de vida e reforça a necessidade de investigação de estratégias focadas na melhora do desempenho no período neonatal.

\section{CONCLUSÃO}

A suplementação oral de cultura de levedura e de levedura enzimaticamente hidrolisada foi capaz de reduzir os efeitos dos desafios provocados pelo sistema de criação ao ar livre, uma vez que reduziu as taxas de diarreia com causa infecciosa em bezerras até seis semanas de vida, apesar de não ter afetado o desenvolvimento corporal desses animais.

\section{AGRADECIMENTOS}

Esta pesquisa foi apoiada pelo CNPq (UNIVERSAL - MCTI / CNPq n 14/2014) e FAPERGS (PqG 02/2014).

\section{BIBLIOGRAFIA}

Al-Alo, K,Z,K, Nikbakht Brujeni, G, H, Lotfollahzadeh, S, Moosakhani, F, \& Gharabaghi, A 2018, 'Correlation between neonatal calf diarrhea and the level of maternally derived antibodies'. Iranian Journal of Veterinary Research, vol. 19, n. 1), pp. 3-8.

Borges, A, S, Feitosa, F, L, F, Benesi, F,J, Birgel, E,H \& Mendes, L,C,N 2001, Influência da forma de administração e da quantidade fornecida de colostro sobre a concentração de proteína total e de suas frações eletroforéticas no soro sangüíneo de bezerros da raça Holandesa', Arquivos Brasileiro de Medicina Veterinária e Zootecnia, vol. 53, n. 5, pp. 629-634.

Boudergue, C, Burel, C, Dragacci, S, Favrot, M, Fremy, J, Massimi, C, Prigent, P, Debongnie, P, Pussemier, L, Boudra, H, Morgavi, D, Oswald, I, Perez, A, \& Avantaggiato, G, 2009, 'Review of mycotoxin-detoxifying agents used as feed additives: mode of action, efficacy and feed/ food safety', EFSA Supporting Publications, vol. 6, n. 9, pp. 1-192.

Brandi, R,A, Tribucci, A, M, de, Balieiro, J, C, de C, Souza, R, L, M, de, Pereira, A, M, F, \& Hoffman, R, M, 2016, 'Physicochemical and microbial analysis of feces from horses fed diets containing citrus pulp', Ciência Animal Brasileira, vol. 17, n. 4, pp. 527-533.

Campos, A, T, Klosowski, E, S, Gasparino, E, Campos, A, T, de, Santos, W, B, R dos 2005, 'Análise térmica de abrigos individuais móveis e sombrite para bezerros', Acta Scientiarum. Animal Sciences, vol. 27, n. 1, pp. 153-161.

Cho, Y, I., Han, J, I, Wang, C, Cooper, V, Schwartz, K, Engelken, T \& Yoon, K, J 2013, 'Case-control study of microbiological etiology associated with calf diarrhea', Veterinary Microbiology, vol. 166, n. 3-4, pp. 375-85.

Coelho, S, G 2009, 'Desafios na criação e saúde de bezerros', Ciência Animal Brasileira, VIII Congresso Brasileiro de Buiatria - ANAIS 1. pp. 1-16.

Cole, N, A, Purdy, C, W \& Hutcheson, D, P 1992, 'Influence of yeast culture on feeder calves and lambs', Journal of Animal Science, vol. 70, n. 6, pp. 1682-1690.

Coppola, M, M, Conceição, F, R \& Gil-Turnes, C 2005, 'Effect of Saccharomyces boulardii and Bacillus cereus var. toyoi on the humoral and cellular response of mice to vaccines', Food and Agricultural Immunology, vol. 16, n. 3), pp. 213-219.

Czech, A, Smolczykb, A, Ognika, K, Wlazłoc, L, Nowakowicz-Dębekc, B \& Kiesza, M 2018, 'Effect of dietary supplementation with Yarrowia lipolytica or Saccharomyces cerevisiae yeast and probiotic additives on haematological parameters and the gut microbiota in piglets', Research in Veterinary Science, vol. 119, pp. 221-227.

Ding, J, Zhou, Z, M, Ren, L, P, \& Meng, Q, X 2008, 'Effect of monensin and live yeast supplementation on growth performance nutrient digestibility, carcass characteristics and ruminal fermentation parameters in lambs fed steam-flaked corn-based diets', Asian-Australasian Journal of Animal Sciences, vol. 21, n. 4, pp. 547-554.

European Centre for Disease Prevention and Control (ECDC) 2014. Acessado em: 19/06/2020. Disponível em: <https://www.ecdc. europa.eu/en/publications-data/antibiotic-resistance-how-does-antibiotic-resistance-spread>.

European Food Safety Authority (EFSA) 2015. Acessado em: 19/06/2020. Disponível em: <https://ec.europa.eu/commission/ presscorner/detail/pt/IP_18_6405>

European Food Safety Authority (EFSA) 2019, 'Assessment of the application for renewal of authorization of Biosprint $₫$ (Saccharomyces cerevisiae MUCL 39885) for dairy cows and horses', EFSA Journal, vol. 17, n. 11, pp. 5915-5922.

European Food Safety Authority (EFSA) 2020, 'Assessment of the application for renewal of authorization of selenium-enriched yeast produced 
by Saccharomyces cerevisiae CNCM I-3399 for all animal species', EFSA Journal, vol. 18, n. 5, pp. 6144-6154.

Fairchild, A, S, Grimes, J, L, Jones, F, T, Wineland, M, J, Edens, F, W \& Sefton, A, E 2001, 'Effects of hen age, Bio-Mos $\circledast$ and Flavomycin $\circledast$ on poult susceptibility to oral Escherichia coli challenge', Poultry Science, vol. 80, n. 5, pp. 562-571

Ferket, P, R, 2003, 'Controlling gut health without the use of antibiotics' Proceedings of the 30th Annual Carolina Poultry Nutrition Conference. (p. 57-68). North Carolina, USA: Carolina Feed Industry Association - North Carolina State University

Fokkink, W, B, Hill, T, M, Aldrich, J, M, Bateman, H, G, Schlotterbeck, R, L 2009, ' Effect of Yeast Culture, Fatty Acids, Whey, and a Peptide Source on Dairy Calf Performance', Applied animal science, vol. 25, n. 6, pp. 794-800.

Fonseca-Alaniz, M, H, Takada, J, Alonso-Vale, M, I, C, Lima, F, B 2006, 'OTecido Adiposo Como Centro Regulador do Metabolismo', Arquivos Brasileiros Endocrinologia Metabetabolismo, vol. 50, n. 2, pp. 216-229.

Fortuoso, B, F, de, Volpato, A, Rampazzo, L, Glombowsky, P, Griss, L, G, Galli, G, M, Stefani, L, M, Baldissera, M, D, Ferreira, E, B, Machado, G \& Silva, A, S, da. 2018, 'Homeopathic treatment as an alternative prophylactic to minimize bacterial infection and prevent neonatal diarrhea in calves', Microbial Pathogenesis, vol. 114, pp. 95-98.

Gao, J, Zhang, H, J, Yu, S, H, Wu, S, G, Yoon, I, Quigley, J, Gao, Y, P.\& Qi, G, H (2008), 'Effects of yeast culture in broiler diets on performance and immunomodulatory functions' Poultry Science, vol. 87, n.7, pp. 1377-1384.

Ghazanfar, S, Khalid, N, Ahmed, I \& Imran, M 2017, 'Probiotic Yeast: Mode of Action and lts Effects on Ruminant Nutrition. Yeast-Industrial Applications', IntechOpen, pp. 179-202.

Gordon, H, M \& Whitlock, H, V 1939, 'A new technique for counting nematode eggs in sheep faeces', Journal of the Council for Scientific and Industrial Research, vol. 12, n. 1, pp. 50-52.

Gosh, S, Mehla, R, K, Sirohi, S, K \& Tomar, S, K 2011 , 'Performance of crossbred calves with dietary supplementation of garlic extract', Journal of Animal Physiology and Animal Nutrition, vol. 95, n.4, pp. 449-455.

Habing, G, Harris, K, Schuenemann, G, M, Piñeiro, J, M, Lakritz, J \& Claviijo, X, A 2017, 'Lactoferrin reduces mortality in preweaned calves with diarrhea', Journal of Dairy Science, vol. 100, n. 5, pp. 3940-3948

Haddad, S, G \& Goussous, S, N 2005, `Effect of yeast culture supplementation on nutrient intake, digestibility and growth performance of Awassi lambs', Animal Feed Science Technology, vol. 118, pp. 343-348.

Hänninen, L, Hepola, H, Rushen, J, Passillé, A, M, Pursiainen, P, Tuure, V, Syriälä-qvist, L, Pyykkönen, M, Saloniemi, H 2003, 'Resting Behaviour, Growth and Diarrhoea Incidence Rate of Young Dairy Calves Housed Individually or in Groups in Warm or Cold Buildings', Acta Agriculturae Scandinavica, Section A - Animal Science, vol. 53, n. 1, pp. 21-28. Hepolaa, H, Hänninenb, L, Pursiainena, P, V, Tuurec, L, Syriälä-Qvista, M, Pyykkönend, M, Saloniemib, H 2006, 'Feed intake and oral behaviour of dairy calves housed individually or in groups in warm or cold buildings', Livestock Science, vol. 105, n. 1-3, pp. 94-104.

Herbrecht, R, Nivoix, Y 2005, 'Saccharomyces cerevisiae Fungemia: An Adverse Effect of Saccharomyces boulardii Probiotic Administration', Clinical Infectious Diseases, vol. 40, n. 11, pp. 1635-1637.

Huuskonen, A \& Pesonen, M 2015, 'The Kielanowski Institute of Animal Physiology and Nutrition PAS, Jabłonna Does yeast (Saccharomyces cerevisiae) supplementation in calf starter modify feed intake and liveweight gain of dairy bull calves?', Journal of Animal and Feed Sciences, vol. 24, pp. 295-301

Jiang, Y, Ogunade, I, M, Arriola, K, G, Qi, M, Vyas, D, Staples, C, R \& Adesogan, A, T 2017, 'Effects of the dose and viability of Saccharomyces cerevisiae. 2. Ruminal fermentation, performance of lactating dairy cows, and correlations between ruminal bacteria abundance and performance measures', Journal of Dairy Science, vol. 100, n. 10 , pp.8102-8118.
Johnsen, J, F, Zipp, K, A, Kälber, T, Passillé, A, M, de, Knierim, U, Barth, $K$ \& Mejdell, C, M 2016, 'Is rearing calves with the dam a feasible option for dairy farms? Current and future research', Applied Animal Behaviour Science, vol. 181, pp.1-11.

Kim, M, H, Seo, J, K, Yun, C, H, Kang, S, J, Ko, J, Y \& Há, J, K 2011 , 'Effects of hydrolyzed yeast supplementation in calf starter on immune responses to vaccine challenge in neonatal calves`. Animal, vol. 5, n. 6, pp. 953-960.

Klein-Jöbstl, D, Iwersen, M \& Drillich, M 2014, 'Farm characteristics and calf management practices on dairy farms with and without diarrhea: $A$ case-control study to investigate risk factors for calf diarrhea', Journal of Dairy Science, vol. 97, n. 8, pp. 5110-5119.

Kuczaj, M, Czerniawsla-Piatkowska, E, Mizera, A, Pilarczyk, R, Pilarczyk, B \& Barton, P 2019, 'The Impact of Selected Breeding and Environmental Factors on the Efficiency of Rearing Calves', Pakistan Journal of Zoology, vol. 51, n. 3, pp. 955-960.

Lin, C, Y, Alexander, C, Steelman, A, J, Warzecha, C, M, Godoy, M, $R, C$ \& Swanson, K, S 2019, 'Effects of a Saccharomyces cerevisiae fermentation product on fecal characteristics, nutriente digestibility, fecal fermentative end-products, fecal microbial populations, immune function, and diet palatability in adult dogs', Journal of Animal Science, vol. 97, n. 4, pp. 1586-1599.

Lora, I, Gottardo, F, Contiero, B, Dall Ava, B, Bonfanti, L, Stefani, A \& Barberio, A 2018, 'Association between passive immunity and health status of dairy calves under 30 days of age', Preventive Veterinary Medicine, vol. 152, pp. 12-15.

Machado Neto, R., Faroni, C, E, Pauletti, P, Bessi, R 2004, 'Levantamento do manejo de bovinos leiteiros recém-nascidos: desempenho e aquisição de proteção passiva', Revista Brasileira de Zootecnia, vol. 33, n. 6, pp. 2323-2329

Magalhães, V, J, Susca, F, Lima, F, S, Branco, A, F, Yoon, I \& Santos, J, $E$ 2008, 'Effect of feeding yeast culture on performance, health, and immunocompetence of dairy calves', Journal of Dairy Science, vol. 91, n. 4, pp. 1497-1509.

Marden, J, P, Julien, C, Monteils, V, Auclair, E, Moncoulon, R \& Bayourthe, C 2008, 'How does live yeast differ from sodium bicarbonate to stabilize ruminal $\mathrm{pH}$ in high-yielding dairy cows?,' Journal of Animal Science, vol. 91, n. 9, pp. 3528-3535.

Maunsell, F \& Donovan, G, A 2008, 'Biosecurity and Risk Management for Dairy Replacements', Veterinary Clinics of North America - Food Animal Practice, vol. 24, n. 1), pp. 155-190.

Narimatsu, F, C, Lima, S, M, R, R, Ueda, S, M, Y, da Silva Carramão, $S$ \& Gamberini, M, T 2019, 'Avaliação in vitro da associação medicamentosa de extrato bruto de Allium sativum L.(alho) com Imipenem e Meropenem frente a cepas sensíveis de Escherichia coli. 'Arquivos Médicos dos Hospitais e da Faculdade de Ciências Médicas da Santa Casa de São Paulo, vol. 64, n. 3, pp. 179-183.

National Research Council 2001, Nutrient requirements of dairy cattle, Washinton, DC: National Academies Press.

Nocek, J, E, Holt, M, G \& Oppy, J 2011 , 'Effects of supplementation with yeast culture and enzymatically hydrolyzed yeast on performance of early lactation dairy cattle', Journal of Dairy Science, vol. 94, n. 8, pp. 4046-4056.

Parks, C, W, Grimes, J, L, Ferket, P, R. \& Fairchild, A, S 2001, 'The effect of mannanoligosaccharides, bambermycins, and virginiamycin on performance of large white male market turkeys', Poultry Science, vol. 80, n. 6, pp. 718-723.

Patês, N, M, da S, Figueiredo, M, P, de, Pires, A, J, V, Carvalho, G, G, P, de, Silva, F, F, da, Fries, D, D, Bonomol, P \& Rosa, R, C, C 2012, 'Production aspects and dairy herd health in dairy farms located in southwestern of Bahia', Revista Brasileira de Saúde e Produção Animal, vol.13, n. 3), pp. 825-837.

Pianta, C 1993, 'Bacterial causes of diarrhea in neonatal calves', Ciência Rural, vol. 23, n. 1), pp. 107-115.

Pinos-Rodríguez, J, M, Robinson, P, H, Ortega, M, E, Berry, S, L, Mendoza, G, Bárcena, R 2008, 'Performance and rumen fermentation of dairy calves supplemented with Saccharomyces cerevisiae 1077 or 
Saccharomyces boulardii 1079', Animal Feed Science and Technology, vol. 140, n. 3-4, pp. 223-232.

Pitarch, A, Nombela, C \& Gil, C 2008, 'Cell wall fractionation for yeast and fungal proteomics', Methods in Molecular Biology, vol. 425, n. 2, pp. 217-239

Robinson, P, H \& Erasmus, LJ 2009, 'Effects of analyzable diet components on responses of lactating dairy cows to Saccharomyces cerevisiaebased yeast products: A systematic review of the literature', Animal Feed Science and Technology, vol. 149, n. 3-4, pp. 185-198.

Roland, L, Drillich, M, Iwersen, M 2014, ' Hematology as a diagnostic tool in bovine medicine',

Journal of Veterinary Diagnostic Investigation, vol. 26, n.5, pp. 1-7.

Roy, U, Jessani, L, G, Rudramurthy, S, M, Gopalakrishnam, R, Dutta, S, Chakravarty, C, Jillwin, J, Chakrabarti, A 2017, 'Seven cases of Saccharomyces fungaemia related to use of probiotics', Mycoses, pp. 1-6.

Sampaio, N, S 1990, 'Estudo das regiões corporais dos bovinos de importância nos julgamentos. In: Exterior e julgamento de bovinos', 4.ed. Piracicaba: FEALQ. pp.27-29.

Sato, T, Hidaka, K, Mishima, T, Nibe, K, Kitahara, L, Hidaka, Y, Katamoto, $\mathrm{H} \&$ Kamimura, S 2010, 'Effect of sugar supplementation on rumen protozoa profile and papillae development in retarded growth calves', Journal of Veterinary Medical Science, vol. 72, n. 11, pp. 1471-1474.

Scibilia, L, S, Muller, L, D, Kensinger, R, S, Sweeney, T, F, Shellenberger, $P, R$ 1987, 'Effect of environmental temperature and dietary fat on growth and physiological responses of newborn calves', Journal of Dairy Science, vol. 70, pp. 1426-1433.

Shen, Y, B, J, A, Carroll, I, Yoon, R, D, Mateo \& S, W, Kim 2011, 'Effects of supplementing saccharomyces cerevisiae fermentation product in sow diets on performance of sows and nursing piglets', Journal of Animal Science, vol. 89, n. 8, pp. 2462-2471.

Silva Junior, F, A, Carvalho, A, H, O, Rocha, C, M, B, M, Guimarães, A, $M 2011$. 'Fatores de risco associados à infecção por Cryptosporidium spp. e Giardia duodenalis em bovinos leiteiros na fase de cria e recria na mesorregião do Campo das Vertentes de Minas Gerais'. Pesquisa Veterinária Brasileira, vol. 31, pp. 690-696.

Silva, L, G, C, da, Cavazini, I, M, Feijó, J, de O, Corrêa, M, N, Del Pino, $F, A, B$ \& Rabassa, V, R 2019, 'Fast action enrofloxacin associated with oral electrolyte and energy replacement or endovenonous fluid therapy in the treatment of neonatal bovine diarrhea'. Ciência Animal Brasileira, vol. 20, pp. 1-10.

Solarte, A, L, Astorga, R, J, Aguiar, F, Relanõ, A, G, Maldonado, A \& Huerta, B 2017, 'Combination of Antimicrobials and Essential Oils as an Alternative for the Control of Salmonella enterica Multiresistant Strains Related to Foodborne Disease', Foodborne Pathogens and Disease, vol. XX, pp.1-6.

Spring, P, Wenk, C, Dawson, K, A., Newman, K, E 2000, 'The effects of dietary mannanoligosaccharides on cecal parameters and the concentrations of enteric bacteria in the ceca of salmonella-challenged broiler chicks', Poultry Science, vol. 79, n. 2, pp. 205-211.

Terentjeva, M, Streikiša, M, Avsejenko, J, Trofimova, J, Kovalıenko, K, Elferts, D \& Bērzingš, A 2018, 'Prevalence and Antimicrobial Resistance of Escherichia coli, Enterococcus spp. and the Major Foodborne Pathogens in Calves in Latvia', Foodborne Pathogens and Disease, vol. 16, n. 1, pp. 35-41.

Torrezan, T, M, Silva, J, T, da, Miqueo, E, Rocha, N, B, Silva, F, L, M, Baldassin, S \& Bittar, C, M, M 2016, 'Desempenho de bezerros leiteiros recebendo probiótico contendo Bacillus subtilis e Bacillus licheniformis', Revista Brasileira de Saúde e Produção Animal, vol. 17, n. 3, pp. 508-519.

Vetvicka, V \& Vetvickova, J 2007, 'Physiological effects of differenttypes of $\beta$-glucan', Biomedical papers of the Medical Faculty of the University Palacky, Olomouc, Czechoslovakia, vol. 151, n. 2, pp. 225-231.

Wójcik, A, Nałęcz-Tarwacka, T \& Gołębiewski, M 2013, 'Comparison of calves rearing parameters in two different housing systems: Indoor versus outdoor hutches', Archiv fur Tierzucht, vol. 63, pp. 628-637. Zhu, W, Wei, Z, Xu, N, Yang, F, Yoon, I, Chung, Y, Liu, J, Wang, J 2017, 'Effects of Saccharomyces cerevisiae fermentation products on performance and rumen fermentation and microbiota in dairy cows fed a diet containing low quality forage', Journal of Animal Science and Biotechnology, vol. 8, n. 1, pp. 36-45. 